\title{
The SYNTAX score on its way out or ... towards artificial intelligence: part I
}

Serruys, Patrick W ; Chichareon, Ply ; Modolo, Rodrigo ; Leaman, David M ; Reiber, Johan H C ; Emanuelsson, Håkan ; Di Mario, Carlo ; Pijls, Nico H J ; Morel, Marie-Angèle ; Valgimigli, Marco ; Farooq, Vasim ; van Klaveren, David ; Capodanno, Davide ; Andreini, Daniele ; Bourantas, Christos V ; Davies, Justin ; Banning, Adrian P ; Escaned, Javier ; Piek, Jan J ; Echavarría-Pinto, Mauro ; Taylor, Charles Anthony ; Thomsen, Brian ; Collet, Carlos ; Pompilio, Giulio ; Bartorelli, Antonio L ; Glocker, Ben ; Dressler, Ovidiu ; Stone, Gregg W ; Onuma, Yoshinobu

DOI: https://doi.org/10.4244/EIJ-D-19-00543A

Posted at the Zurich Open Repository and Archive, University of Zurich ZORA URL: https://doi.org/10.5167/uzh-191754

Journal Article

Published Version

Originally published at:

Serruys, Patrick W; Chichareon, Ply; Modolo, Rodrigo; Leaman, David M; Reiber, Johan H C; Emanuelsson, Håkan; Di Mario, Carlo; Pijls, Nico H J; Morel, Marie-Angèle; Valgimigli, Marco; Farooq, Vasim; van Klaveren, David; Capodanno, Davide; Andreini, Daniele; Bourantas, Christos V; Davies, Justin; Banning, Adrian P; Escaned, Javier; Piek, Jan J; Echavarría-Pinto, Mauro; Taylor, Charles Anthony; Thomsen, Brian; Collet, Carlos; Pompilio, Giulio; Bartorelli, Antonio L; Glocker, Ben; Dressler, Ovidiu; Stone, Gregg W; Onuma, Yoshinobu (2020). The SYNTAX score on its way out or ... towards artificial intelligence: part I. EuroIntervention, 16(1):44-59.

DOI: https://doi.org/10.4244/EIJ-D-19-00543A 


\title{
The SYNTAX score on its way out or ... towards artificial intelligence: part I
}

\author{
Eurolntervention 2020;16:44-59. DOI: 10.4244/EIJ-D-19-00543A
}

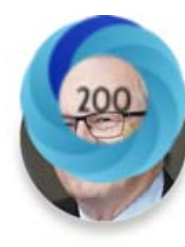

Patrick W. Serruys ${ }^{7}$, MD, PhD; Ply Chichareon 2,3, MD; Rodrigo Modolo2,4, MD; David M. Leaman5, MD; Johan H.C. Reiber6, PhD; Håkan Emanuelsson7, MD; Carlo Di Mario ${ }^{8}$, MD, PhD; Nico H.J. Pijls9,10, MD, PhD; Marie-Angèle Morel11, BSc; Marco Valgimigli12, MD, PhD; Vasim Farooq ${ }^{13}$, MD, PhD; David van Klaveren ${ }^{14}$, PhD; Davide Capodanno ${ }^{15}, \mathrm{MD}, \mathrm{PhD}$; Daniele Andreini ${ }^{16,17}, \mathrm{MD}$, PhD; Christos V. Bourantas $^{18}$, MD, PhD; Justin Davies', MD, PhD; Adrian P. Banning ${ }^{19}$, MD; Javier Escaned ${ }^{20}$, MD, PhD; Jan J. Piek ${ }^{2}$, MD, PhD; Mauro Echavarría-Pinto ${ }^{2}$, MD, PhD; Charles Anthony Taylor ${ }^{27}$, PhD; Brian Thomsen 22, MSc; Carlos Collet2,23, MD; Giulio Pompilio ${ }^{16,17}$, MD, PhD; Antonio L. Bartorelli ${ }^{16,24}$, MD; Ben Glocker $^{25}$, PhD; Ovidiu Dressler ${ }^{26}$, MD; Gregg W. Stone ${ }^{27}$, MD; Yoshinobu Onuma 28, MD, PhD

7. NHLI, Imperial College London, London, United Kingdom; 2. Amsterdam UMC, University of Amsterdam, Heart Center, Department of Clinical and Experimental Cardiology, Amsterdam Cardiovascular Sciences, Amsterdam, the Netherlands; 3. Cardiology Unit, Department of Internal Medicine, Faculty of Medicine, Prince of Songkla University, Songkhla, Thailand; 4. Department of Internal Medicine, Cardiology Division, University of Campinas (UNICAMP), Campinas, Brazil; 5. Milton Hershey Medical Center, Penn State Heart and Vascular Institute, Hershey, PA, USA; 6. Department of Radiology, Division of Image Processing, Leiden University Medical Center, Leiden, the Netherlands; 7. Astra Charnwood Clinical R and D, Loughborough, United Kingdom; 8. Division of Structural Interventional Cardiology, Careggi University Hospital, Florence, Italy; 9. Department of Cardiology, Catharina Hospital, Eindhoven, the Netherlands; 10. Department of Biomedical Engineering, Eindhoven University of Technology, Eindhoven, the Netherlands; 11. Cardialysis BV, Rotterdam, the Netherlands; 12. Department of Cardiology, Bern University Hospital, Bern, Switzerland; 13. University Hospital of Wales, Cardiff, United Kingdom; 14. Department of Public Health, Erasmus University Medical Center, Rotterdam, the Netherlands; 15. Division of Cardiology, Cardio-Thoracic-Vascular Department, Azienda Ospedaliero Universitaria "Policlinico-Vittorio Emanuele", Catania, Italy; 16. Centro Cardiologico Monzino, IRCCS, Milan, Italy; 17. Department of Clinical Sciences and Community Health, University of Milan, Milan, Italy; 18. Department of Cardiology, Barts Heart Centre, Barts Health NHS Trust, London, United Kingdom; 19. Oxford Heart Centre, Oxford University Hospitals NHS Foundation Trust, Oxford, United Kingdom; 20. Department of Cardiology, Hospital Clinico San Carlos, Madrid, Spain; 21. HeartFlow, Redwood City, CA, USA; 22. GE Healthcare, Waukesha, WI, USA; 23. Cardiovascular Center Aalst, OLV Clinic, Aalst, Belgium; 24. Department of Biomedical and Clinical Sciences "Luigi Sacco", University of Milan, Milan, Italy; 25. Biomedical Image Analysis Group, Department of Computing, Imperial College London, London, United Kingdom; 26. Cardiovascular Research Foundation, New York, NY, USA; 27. The Zena and Michael A. Wiener Cardiovascular Institute, Icahn School of Medicine at Mount Sinai, New York and the Cardiovascular Research Foundation, New York, NY, USA; 28. Department of Cardiology, Thoraxcenter, Erasmus Medical Center, Rotterdam, the Netherlands

\section{Preamble}

Recent publications on the SYNTAX (SYNergy between percutaneous coronary intervention with TAXuS and cardiac surgery) score have caught our attention and triggered a written reaction on the history and evolution of the SYNTAX score over the last decades. Among these publications, there is the editorial of Marie-Claude Morice, "Has the SYNTAX score become obsolete?"1. The most recent guidelines on 
The SYNTAX score on its way out or ... towards artificial intelligence: p... https://eurointervention.pcronline.com/article/the-syntax-score-on-its-wa...

even if the rate of mortality at four years in the EXCEL study was not yet available at the time ...

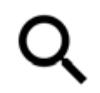

SIGN IN TO READ AND DOWNLOAD THE FULL ARTICLE

\section{LOGIN}

Forgot your password?

\section{NO ACCOUNT YET?}

SIGN UP FOR FREE!

\section{CREATE MY PCR ACCOUNT}

Join us for free and access thousands of articles from Eurolntervention, as well as presentations, videos, cases from PCRonline.com

\section{Read next article}

The SYNTAX score on its way out or ... towards artificial intelligence: part II

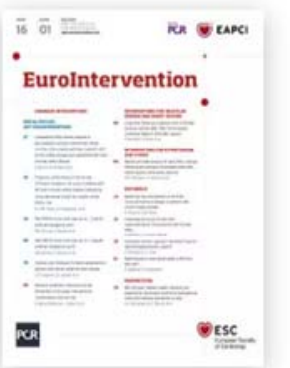

\section{RELATED ISSUE}

\section{Volume 16 Number 1}

> VIEW CONTENTS

\section{TOOLBOX}

Print article

Citations

Ask for a reprint

Request permissions 


\section{Dimensions Badge}

3 iviul vilutions

3 Recent citations

n/a Field Citation Ratio

n/a Relative Citation Ratio

\section{Altmetric}

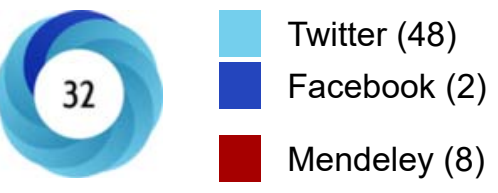

\section{POPULAR THIS MONTH}

An EAPCI Expert Consensus Document on Ischaemia with Non-Obstructive Coronary Arteries in Collaboration with European Society of Cardiology Working Group on Coronary Pathophysiology \& Microcirculation Endorsed by Coronary Vasomotor Disorders International Study Group.

Vijay Kunadian et al

Impact of the COVID-19 pandemic on interventional cardiology practice: results of the EAPCI survey

Marco Roffi et al

Double-kissing culotte technique for coronary bifurcation stenting Gabor G. Toth et al

2018 ESC/EACTS Guidelines on myocardial revascularization

Franz-Josef Neumann et al

Percutaneous recanalisation of chronic total occlusions: 2019 consensus document from the EurocTO Club

Alfredo R. Galassi et al

\section{LATEST NEWS}

NEW ISSUE

Radiation protection, ticagrelor monotherapy, the COMPARE-ABSORB trial, the BASILICA technique...

NOVEMBER 12, 2020

in 
NEW

Impact of Intervention strategies after failed TMVR

NOVEMBER 12, 2020

EDITORIAL

ASA-free strategy in ACS

Usman Baber

NOVEMBER 12, 2020

Popular Tavi-A, TAILOR-PCI, ATPCI, PORTICO-IDE and more (Thanks to the support of Biotronik)

NOVEMBER 12, 2020

GUIDANCE PAPERS

Guidelines, consensus \& position papers

AUGUST 28, 2020

EDITORIAL

Bioresorbable scaffold déjà vu

Dean J. Kereiakes

NOVEMBER 4, 2020 


\section{This Week's JAA's: CT-QFR or myocardial perfusion imaging in patients with coronary stenosis on CTA, Spontaneous distal embolization from plaque erosion...}

NOVEMBER 17, 2020

\section{CORONARY}

Supporting evidence for ST-segment elevation myocardial infarction from optical coherence tomography Satogami $\mathrm{K}$ et al

One-step anatomic and function testing by cardiac CT versus second-line functional testing in symptomatic patients with coronary artery stenosis: head-to-head comparison of CT-derived fractional flow reserve and myocardial perfusion imaging

Westra J et al

A randomized comparison of Coronary Stents according to Short or Prolonged durations of Dual Antiplatelet Therapy in patients with Acute Coronary Syndromes: a pre-specified analysis of the SMART-DATE trial Jang WJ et al

\section{VALVULAR DISEASE}

Fatal Acute Mesenteric Ischemia Following Transcatheter Aortic Valve Replacement del Val D et al

Clinical Impact of Intervention Strategies after failed Transcatheter Mitral Valve Repair Alessandrini $\mathrm{H}$ et al

Percutaneous mitral valve leaflet repair: ongoing directions and future perspectives Maisano F, Taramasso M

\section{HEART FAILURE}

The EURO SHOCK Trial: Design, Aims and Objectives Randomised comparison of Extra Corporeal Membrane Oxygenation (ECMO) delivered after acute-PCI plus standard of care versus standard of care alone after acute $\mathrm{PCl}$, in patients presenting with Acute Coronary syndrome and Cardiogenic Shock.

Banning $A$ et al

Percutaneous mitral valve leaflet repair: ongoing directions and future perspectives

Maisano F, Taramasso M

Deep Sedation versus General Anaesthesia for Transcatheter Mitral Valve Repair: An Individual-Patient Data Meta-analysis of Observational Studies.

Jobs A et al 


\section{DERIPHERAL}

Multistage Strategy With Perfusion SPECT and CT Pulmonary Angiogram in Balloon Pulmonary Angioplasty for Totally Occluded Lesions in CTEPH

Hosokawa K et al

EAPCI Core Curriculum for Percutaneous Cardiovascular Interventions (2020): Committee for Education and Training European Association of Percutaneous Cardiovascular Interventions (EAPCI) A branch of the European Society of Cardiology

Van Belle E et al

Fistula between the right pulmonary artery and left atrium in a newborn: management and successful interventional treatment.

Michalak K et al

\section{HYPERTENSION}

EAPCI Core Curriculum for Percutaneous Cardiovascular Interventions (2020): Committee for Education and Training European Association of Percutaneous Cardiovascular Interventions (EAPCI) A branch of the European Society of Cardiology

Van Belle E et al

Early Results of the Revivent TC Procedure for Treatment of Left Ventricular Aneurysm and Heart Failure due to Ischemic Cardiomyopathy 8

Wang $Y$ et al

Pulmonary artery denervation using catheter-based ultrasonic energy $\mathbf{a}$

Rothman A et al

\section{STROKE}

Impact of Pulmonary Ridge Coverage after Left Atrial Appendage Occlusion

Freixa $\mathrm{X}$ et al

Heterogeneity of debris captured by cerebral embolic protection filters during TAVI

Kroon $\mathrm{H}$ et al

First-in-human results of the OMEGATM Left Atrial Appendage Occluder for Patients with Non-Valvular Atrial Fibrillation

Wilkins B et al

\section{About the journal}

Editorial team 
Dicclaimer

Privacy policy

\section{Readers}

Current issue

Archives

Subscribe

\section{Authors}

Submit your paper

Instructions

\section{Services}

Advertise

Reprints / ePrints

Rights and permissions

\section{Textbooks}

The PCR-EAPCI textbook

The history of angioplasty

Percutaneous cardiac interventions

Coronary stenosis

\section{Follow us}

Facebook

Twitter

Impact factor: 3.993

2019 Journal Citation Reports $\AA$

Science Edition (Clarivate Analytics, 2020)

Online ISSN 1969-6213 - Print ISSN 1774-024X

(C) 2005-2020 Europa Group - All rights reserved 